\title{
Casa Permeável: uma metodologia projetual alternativa para a concepção de uma habitação unifamiliar
}

Permeable House: an alternative project methodology for designing single family dwellings

\author{
Gustavo Streck Severo ${ }^{1}$, Ricardo de Souza Rocha ${ }^{2}$ e Samuel Silva de Brito ${ }^{3}$ \\ ${ }^{1}$ Universidade Federal de Santa Maria, Cachoeira do Sul, Brasil \\ gustavo.streck.severo@gmail.com \\ ${ }^{2}$ Universidade Federal de Santa Maria, Cachoeira do Sul, Brasil \\ ricardo.rocha@ufsm.br \\ ${ }^{3}$ Universidade Federal de Santa Maria, Cachoeira do Sul, Brasil \\ samuel.brito@ufsm.br
}

\section{Resumo}

Casa Permeável é o título do trabalho realizado dentro da disciplina "Projeto III" do Curso de Arquitetura e Urbanismo da Universidade Federal de Santa Maria (Campus Cachoeira do Sul) no primeiro semestre de 2017, que trata de um projeto de habitação unifamiliar. Ao confrontarmos a tradicional residência familiar fomos conduzidos através de uma peculiar metodologia de trabalho que enfatiza certas demandas e provoca raciocínios de projeto sensiveis a questões vitais inusitadas. Este trabalho objetiva apresentar as particularidades deste processo de projeto encaminhando-se a um resultado especifico, a Casa Permeável - uma alternativa experimental à organização usual do programa de uma habitação -, identificando o renovado entendimento da arquitetura sob os pontos de vista desta metodologia que enfatiza a estrutura - e a oportunidade de concebê-la junto com as inquirições iniciais da forma -, a cidade - ao perceber a arquitetura como um ente que realiza o espaço urbano - e a paisagem - ao valorizar a competência da arquitetura em dialogar com seu entorno natural e construído.

Palavras-chave: Arquitetura; Habitação Unifamiliar; Metodologia

\section{Abstract}

Permeable House is the title of the present paper produced for the "Projeto III" course at the Universidade Federal de Santa Maria (Campus Cachoeira do Sul) as part of the Architecture and Urbanism program in the first semester of 2017, related to single family housing projects. Facing the traditional single-family dwelling, we were guided by a unique work methodology that emphasizes certain requests and elicits a mindset concerned about unexpected vital issues. This paper aims to present the specific features of this design planning method towards a specific outcome: Permeable house - an experimental alternative to the usual organization of house designing - identifying the refreshed understanding of architecture from the point of view of this methodology that emphasizes the structure - and the opportunity of designing it along with the initial concerns over form -, the city - considering architecture as an entity that creates the urban space - and the environment - highlighting the role architecture has when it comes to dialoguing with its natural and built surroundings.

Keywords: Architecture; Single Family Dwellings; Methodology 


\section{Introdução}

Neste artigo são apresentadas as experiências vivenciadas na disciplina Projeto III do Curso de Arquitetura e Urbanismo da Universidade Federal de Santa Maria, Campus Cachoeira do Sul (CAU-UFSM/CS), no primeiro semestre de 2017.

A disciplina, nesta circunstância, objetivou o conhecimento, a análise e a aplicação das variáveis intervenientes na atividade de projetar o ambiente construído destinado à habitação unifamiliar. Dessa forma, mediante contraposições de percepções habituais acerca das particularidades dessa tipologia, de seu processo de concepção projetual e de sua inserção urbana, foi desenvolvida uma metodologia de trabalho específica que ressignificou raciocínios e enfatizou determinadas demandas.

Este artigo, em síntese, corresponde a um relato que objetiva apresentar as singularidades deste processo de projeto com ênfase em um resultado específico, idealizado pelo primeiro autor deste artigo: a Casa Permeável. Divide-se, para tanto, em dois estágios: em um primeiro momento são apresentadas as variáveis pertinentes ao contexto geral da disciplina; em seguida, estabelece-se uma abordagem evidenciando os processos e resultados específicos.

\section{A disciplina Projeto III do CAU-UFSM/CS em 2017/1}

A disciplina Projeto III $^{1}$ destina-se ao tema da habitação unifamiliar. No primeiro semestre de 2017, em concordância a experimentações anteriores, foram propostas discussões acerca da relação entre tipologias residenciais unifamiliares e morfologia urbana.

A abordagem adotada pelos docentes responsáveis, Ricardo Souza Rocha e Samuel Silva de Brito, inseria-se em um processo de reestruturação curricular que, mais tarde, no primeiro semestre de 2018, resultou na substituição do Projeto Pedagógico do Curso (PPC). Anteriormente denominada Ateliê de Projeto de Arquitetura, Urbanismo e Paisagismo III, a disciplina dispunha de uma carga horária de setenta e cinco horas, distribuída em dois encontros semanais.

$\mathrm{O}$ ambiente de trabalho idealizado fundamentou-se na vivência colaborativa de um ateliê. Apoderando-se de atividades práticas, essencialmente manuais - suscitando a experimentação, sobretudo através do uso de maquetes -, breves aulas expositivas e, principalmente, estímulos à racionalidade, os discentes foram encaminhados à ressignificação e desconstrução de raciocínios projetuais convencionais.

A contraposição do tradicional entendimento acerca de uma tipologia residencial unifamiliar, de seu processo de concepção projetual e de sua inserção urbana - de forma individual, em lotes privados -, eixos temáticos fundamentais à disciplina, atingiu maturidade na composição de uma metodologia. De caráter peculiar, concebido de forma experimental e participativa entre docentes e discentes, o renovado processo de projeto adotado em todas as etapas que compreenderam a concepção das habitações qualificou-se por enfatizar a estrutura, a cidade e a paisagem.

A disciplina desenvolveu-se, neste contexto, a partir de três exercícios projetuais específicos: charrete de tipologias em contexto estrutural, masterplan de quadra aberta e anteprojeto arquitetônico de habitação unifamiliar. Apesar de complementares, visto que viabilizaram a construção de raciocínios conexos, esses exercícios sucederam-se de modo independente entre si, distinguindo-se quanto às suas estruturações e objetivos.

\footnotetext{
${ }^{1}$ Com o novo Projeto Pedagógico do Curso de Arquitetura e Urbanismo da UFSM-CS, atualmente a disciplina se intitula "Projeto III". Na ocasião em que foi cursada, no primeiro semestre de 2017, o nome da disciplina era "Ateliê de Arquitetura, Urbanismo e Paisagismo III".
} 
O material produzido ao longo das atividades possuiu, substancialmente, origem manual (maquetes físicas e desenhos técnicos elaborados à mão, por exemplo). A exceção é atribuída à manipulação de software de modelagem tridimensional (SketchUp), utilizado tanto para racionalizar determinados processos quanto para visualizar resultados de forma mais aprimorada. Há que se ressaltar também a realização, ao fim de cada um dos estágios, de painéis de apresentações e discussões coletivas acerca dos resultados obtidos.

\subsection{Charrete de Tipologias em Contexto Estrutural}

O primeiro exercício desenvolvido principiou-se na redução do objeto arquitetônico a um de seus subsistemas mais elementares: a estrutura. Particularizado por seu caráter estritamente experimental, objetivou a inversão do raciocínio projetual usual - que, de modo geral, prioriza a composição formal e volumétrica de uma edificação -, passando para o primeiro plano da concepção arquitetônica a ordenação da estrutura.

A partir de ensaios de prototipagem rápida manual - elaborados em escala reduzida, mediante uso de materiais diversos os discentes, organizados em duplas, foram encaminhados à definição de um contexto estrutural padrão, que pudesse ser replicado, e à posterior adequação de uma tipologia habitacional a esse modelo.

Estas experimentações em modelos tridimensionais não consideravam a existência de um suporte urbano real. Em um segundo momento, inserindo-se em uma quadra genérica quadrada de sessenta metros, as estruturas modulares concebidas foram multiplicadas e organizadas de modo a abrigarem, aproximadamente, vinte unidades residenciais - com áreas variando entre cinquenta e cem metros quadrados.

As atividades citadas compreenderam um período aproximado de duas semanas. Observa-se que o conjunto de resultados obtidos, enquanto turma, compuseram um cenário plural de possibilidades frente à problemática proposta. Parte desses resultados foram utilizados no exercício seguinte (masterplan de quadra aberta) quando da reorganização das duplas de discentes, que passaram a configurar três grupos de quatro integrantes.

A Casa Permeável materializou-se em um contexto estrutural derivado de experimentações principiadas nesta etapa. Proposto pelas discentes Manoela da Rosa Salvador e Júlia Heloísa Souza Lima, este contexto configurava-se como uma estrutura linear composta por pórticos de doze metros de comprimento, distantes entre si em cinco metros, e que apresentam elementos verticais pontualmente inclinados, associados conjuntamente através de angulações.

Figura 1 - Contexto estrutural concebido no exercício inicial e que, posteriormente, abrigou a Casa Permeável

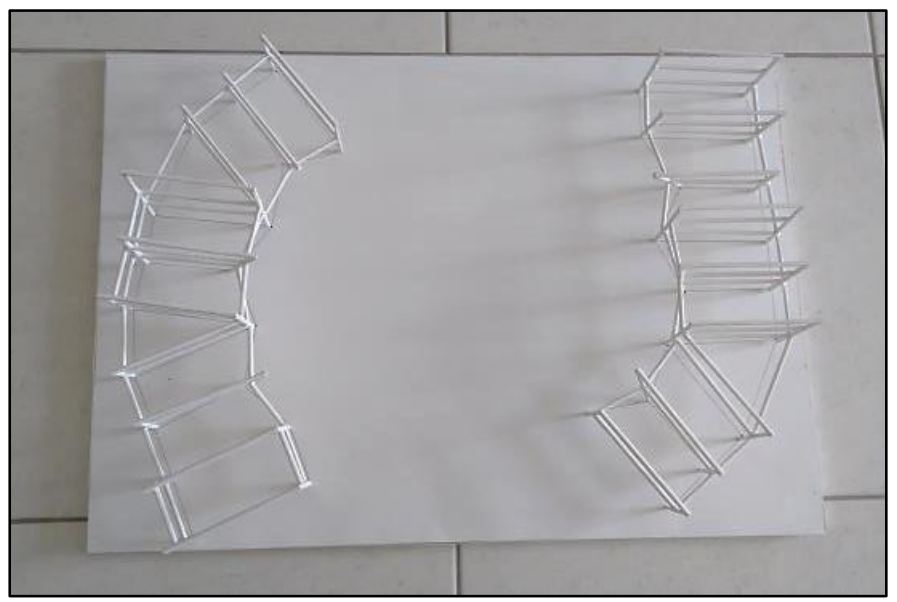




\subsection{Masterplan de Quadra Aberta}

O projeto das habitações unifamiliares foi anteposto pela concepção de um masterplan de uma quadra aberta. Considerando, a partir deste momento, um suporte urbano real - uma área de expansão urbana a noroeste de Cachoeira do Sul, em proximidade às futuras instalações do campus da UFSM-CS, adjacente à Estrada da Ferreira e distante a, aproximadamente, oito quilômetros da região central - foram propostas três quadras - correspondentes aos três grupos de trabalho formados - em formato de trapézios retângulos de base maior e menor medindo, respectivamente, 88,80 e 70 metros, contabilizando 5.556,50 metros quadrados.

Figura 2 - Área de intervenção e conformação proposta para as três quadras

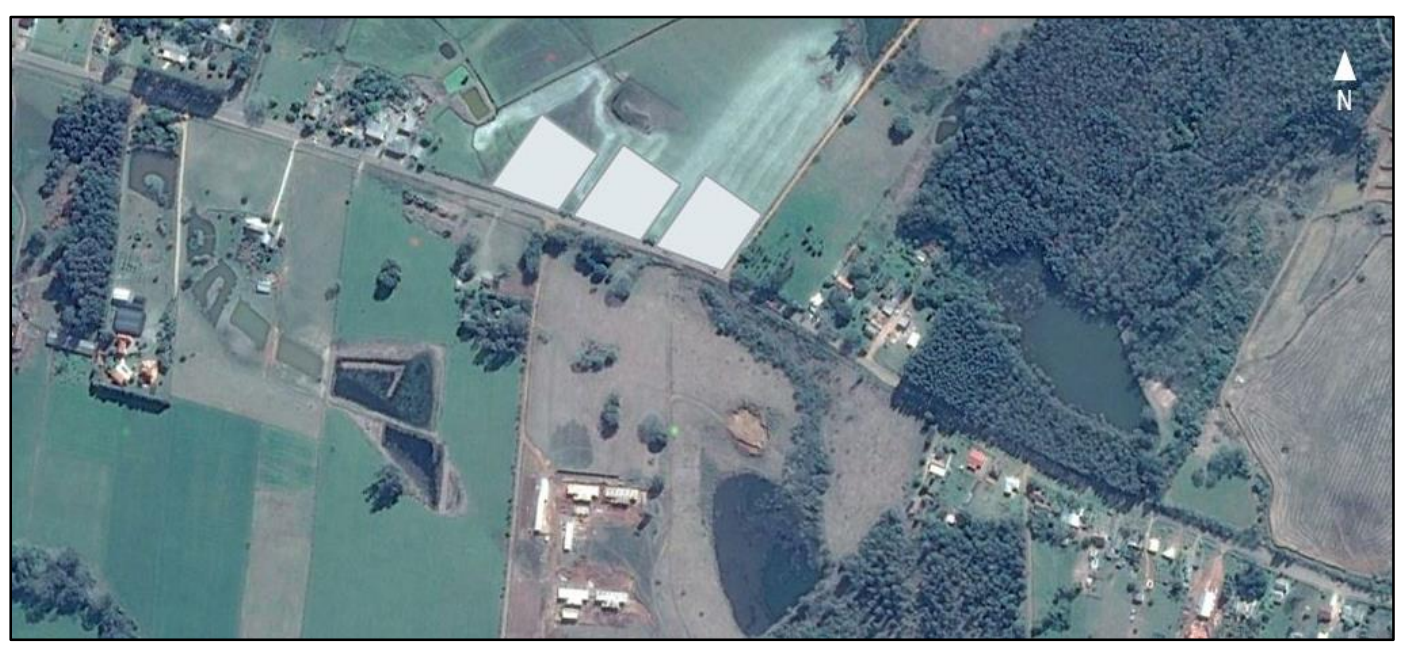

As estruturas modulares oriundas do exercício anterior foram, então, mediante experimentações e proposições de arranjos morfológicos distintos, inseridas em suas respectivas quadras. O enfoque, nesse contexto, passou a ser a relação entre as tipologias residenciais e a morfologia urbana, uma vez que os vazios estruturais, em síntese, configuraram-se como "terrenos verticais" a serem ocupados pelas unidades habitacionais. Observou-se, nessa circunstância, a possibilidade de uma mesma malha estrutural conformar densidades distintas, em conformidade ao tamanho atribuído às unidades.

Diante desta proposta de inserção urbana estabeleceu-se a ocupação integral do térreo das quadras - e das estruturas - por usos alternativos, distintos do uso habitacional, que garantissem diversidade ao contexto da cidade: comércios, prestações de serviços, espaços públicos, entre outros, bem como abrigos para veículos. O uso residencial, portanto, preencheria os níveis superiores e, devido ao seu caráter unifamiliar, demandaria acessos independentes.

Os discentes foram desafiados a conceber variações topográficas que possibilitassem autonomia de percursos e acessos em relação ao último, aos níveis superiores -, desvinculando-se de soluções convencionais (escadas internas privadas, por exemplo). A esse relevo artificial, atribuiu-se o papel de conformação de composições paisagísticas, além de qualificação dos espaços externos.

Tratou-se, portanto, de um processo de definição das escalas urbanas e da paisagem que compreendeu, aproximadamente, cinco semanas. Ao fim desse período, atingiu-se a determinação dos condicionantes necessários para, então, projetar as unidades residenciais. 
A "quadra B" - assim denominada por estar situada no centro do conjunto de três quadras propostas -, na qual insere-se a Casa Permeável, dispõe de uma conformação morfológica concebida a partir da manipulação da malha estrutural, inserida de forma a configurar uma "superestrutura" linear distribuída de modo orgânico, explorando a permeabilidade aos condicionantes ambientais. Estabeleceram-se, dessa forma, basicamente, dois âmbitos de vida pública: um comercial, a sul, adjacente à Estrada da Ferreira, e outro de convivência e contemplação, tanto para moradores, quanto para transeuntes, a norte, onde se situa a maior parte dos acessos aos níveis superiores.

Figura 3 - Perspectiva da quadra B a partir do âmbito de convivência e contemplação

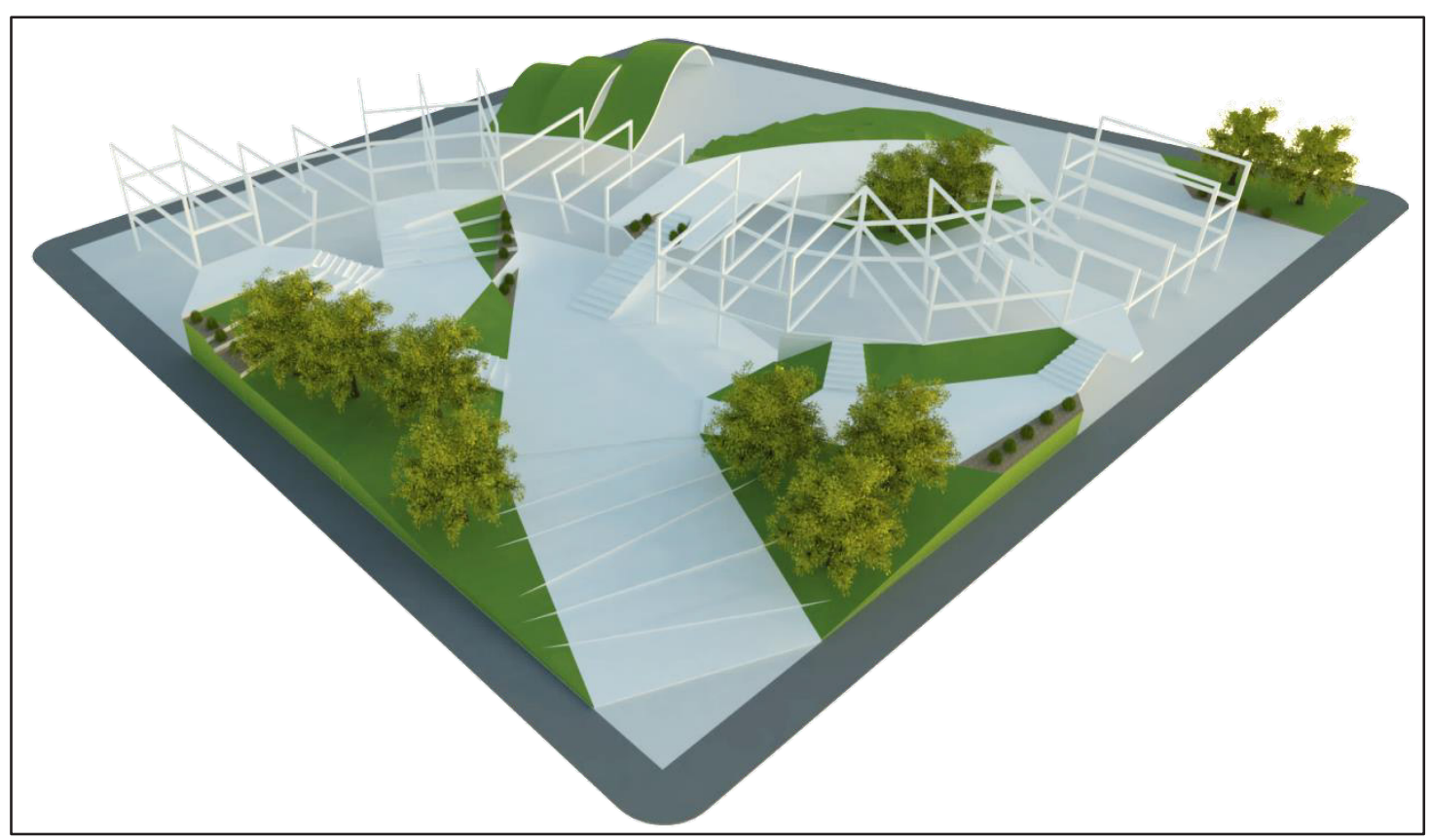

\subsection{Anteprojeto Arquitetônico de Habitação Unifamiliar}

Coube ao último exercício projetual a abordagem debruçada sobre as particularidades da escala arquitetônica. Em um período aproximado de nove semanas, precedido por um estudo preliminar, os discentes atingiram, individualmente, o nível de detalhamento correspondente a um anteprojeto arquitetônico. As habitações unifamiliares previstas dentro do masterplan da etapa anterior foram idealizadas a partir da estrutura predefinida, que deveria ser mantida. Além dos acessos principais determinados pelo relevo, permitiu-se a criação de acessos secundários através de circulações verticais independentes, consoante às intenções específicas de cada projeto.

Os "terrenos verticais" dispostos aos discentes, ainda que de áreas semelhantes no contexto de uma mesma quadra devido à divisão modulada, apresentaram configurações distintas - considerando a ocupação delimitada pela estrutura: um único pavimento; dois pavimentos em todo o perímetro; dois pavimentos, sendo o superior de menor área. A área máxima a ser construída, por sua vez, foi padronizada: cento e cinquenta metros quadrados, sendo permitidas ocupações em balanço - de até um metro e meio para além do perímetro da estrutura. O restante deveria ser manipulado em áreas externas, correspondentes a pátios privados das unidades. 
No caso da quadra B, a área passível de ocupação correspondeu a quatro dos módulos de, aproximadamente, sessenta metros quadrados cada, contabilizando cerca de duzentos e quarenta metros quadrados - valores de áreas aproximadas devido essa estrutura, especificamente, dispor de elementos verticais inclinados que distorcem e reduzem, em determinados módulos, a área total dos planos ("terrenos").

Observa-se que esta metodologia proporcionou aos discentes um processo projetual mais crítico, racional e instigante. Além disso, notabilizou-se o estímulo ao diálogo e à interação, durante o processo projetual, entre discentes vizinhos de unidades habitacionais, uma vez que se sobrepôs o entendimento delas como elementos integrantes de um conjunto - e não como tipologias desconexas, isoladas na malha urbana. Mas, afinal, como projetar uma unidade habitacional a partir de um contexto estrutural preexistente? A Casa Permeável, em meio ao conjunto de condicionantes apresentados, mostrou-se como uma das possibilidades.

\section{Casa permeável}

Casa Permeável é a denominação atribuída à unidade residencial unifamiliar proposta pelo primeiro autor deste artigo como produto final da disciplina Projeto III. Consiste em uma alternativa experimental à organização usual do programa arquitetônico de uma habitação unifamiliar.

Destinada a uma família genérica (um casal e dois filhos) - dispondo, portanto, de um programa de necessidades básico -, apodera-se do conceito de permeabilidade (permear: do latim permeare, que pode ser transpassado). A aplicabilidade do conceito determina a organização do espaço arquitetônico e a relação com o exterior - o que inclui a manipulação dos condicionantes ambientais.

Figura 4 - Perspectiva da Casa Permeável a partir de sua fachada noroeste

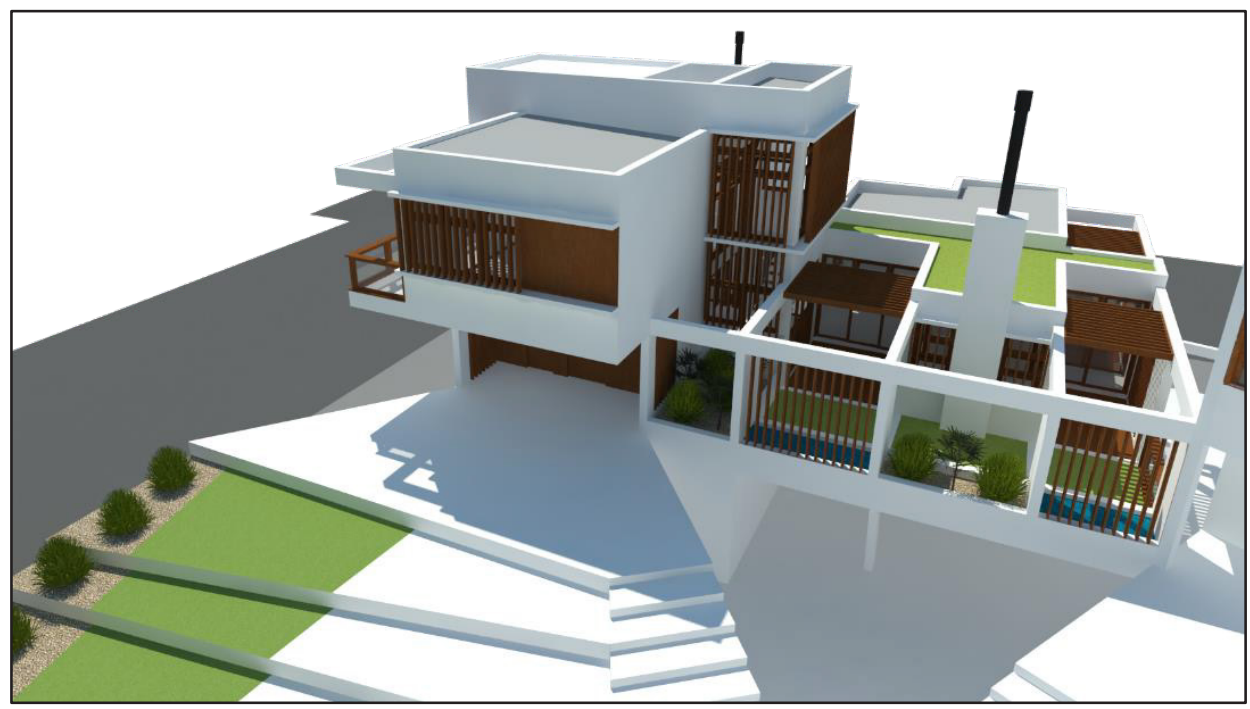

A Casa insere-se na extremidade leste da quadra B e de sua respectiva malha estrutural. Apropria-se de um "terreno vertical" de esquina, dispondo de faces (testadas) de orientações solares intermediárias. O acesso principal realiza-se a noroeste, através de uma sequência de platôs. A conformação da estrutura condicionou à Casa uma ocupação de, aproximadamente, cento e oitenta metros quadrados de área no nível de acesso e sessenta metros quadrados no nível superior passíveis de expansão através de balanços. 
Figura 5 - Identificação dos módulos estruturais correspondentes à Casa Permeável

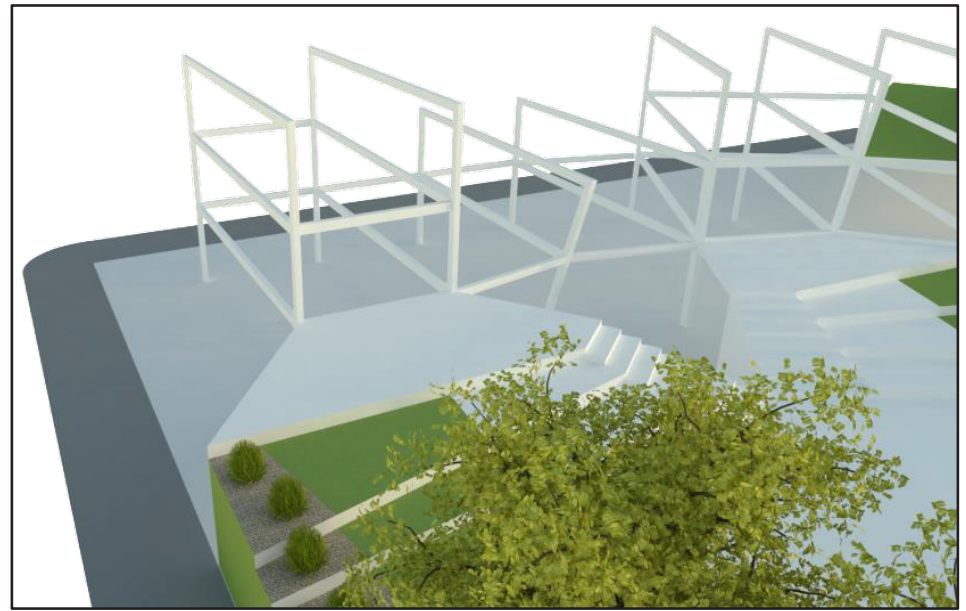

O caráter alternativo designado à metodologia utilizada em sua concepção torna-se evidente quando da distribuição do espaço arquitetônico junto à estrutura preexistente. Observa-se, nesse sentido, que os raciocínios projetuais desenvolvidos foram extremamente influenciados pelos condicionantes predefinidos nas etapas anteriores. Esse processo de concepção, além disso, baseia-se em ensaios projetuais de habitações unifamiliares desenvolvidos pelo escritório paulistano FGMF Arquitetos (Fernando Forte, Lourenço Gimenez e Rodrigo Marcondes Ferraz) - Casa das Pérgolas Deslizantes (Bauru/SP) e Casa Grelha (Serra da Mantiqueira, SP), sobretudo.

\subsection{A Estrutura como Elemento Mediador do Processo Compositivo}

Inúmeras são as possibilidades para principiar o desenvolvimento do projeto arquitetônico de uma residência unifamiliar nas circunstâncias citadas. Cita-se, como exemplo, um processo mediado por experimentações formais e volumétricas fundamentadas nos demais condicionantes físicos, objetivando a melhor disposição do volume edificado no "terreno vertical" e a compatibilização com a estrutura. Observa-se que essa alternativa é bastante oportuna, visto ter sido a percepção que orientou o processo projetual de grande parte dos discentes e propiciou a manifestação de propostas compositivas plurais e significativas.

O raciocínio que pautou a concepção da Casa Permeável, entretanto, foi outro: a proposta derivou-se do completo diálogo com o subsistema estrutural. Não houve, em um primeiro momento, a exploração e o aprimoramento de formas. A concepção iniciou-se mediante experimentações bidimensionais de organização espacial. Estabeleceu-se, por conseguinte, o acréscimo de uma nova modulação ao contexto estrutural preexistente, manifestada de modo rítmico e ordenado, transversal e longitudinalmente. A fragmentação obtida permitiu e apreensão da espacialidade da estrutura e das distintas possibilidades de estruturação dos ambientes em planta.

O processo compositivo da Casa fundamentou-se, portanto, em uma investigação espacial da estrutura. Esse raciocínio, embasado na racionalidade, permitiu o completo domínio do processo e a disposição ordenada do programa arquitetônico, que se realizou, ademais, de modo concordante aos condicionantes ambientais, mediante a aplicabilidade de conceitos bioclimáticos. 
Figura 6 - Modulação estabelecida no sentido transversal à estrutura preexistente (em vermelho e preto, respectivamente) visualizada nas plantas baixas do segundo (a) e terceiro pavimento (b)

(a)

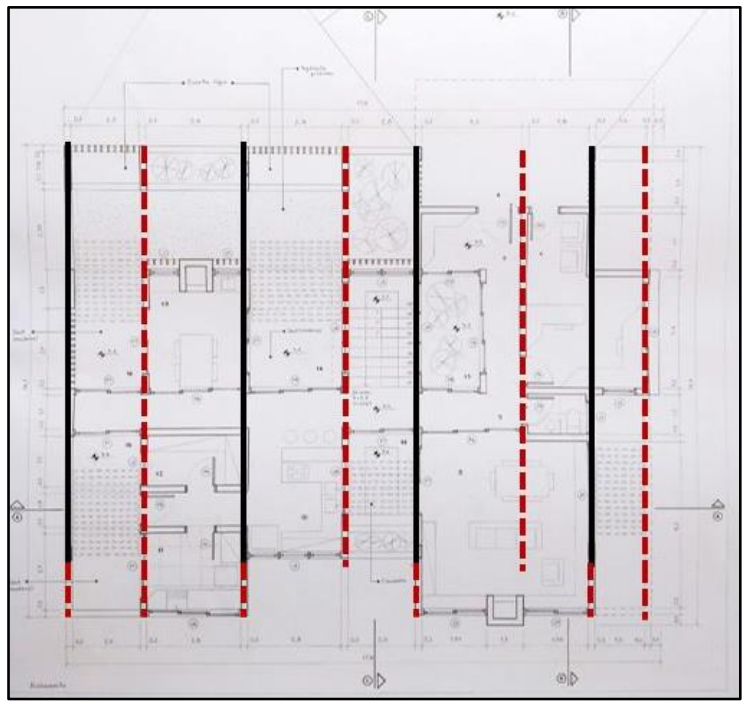

(b)

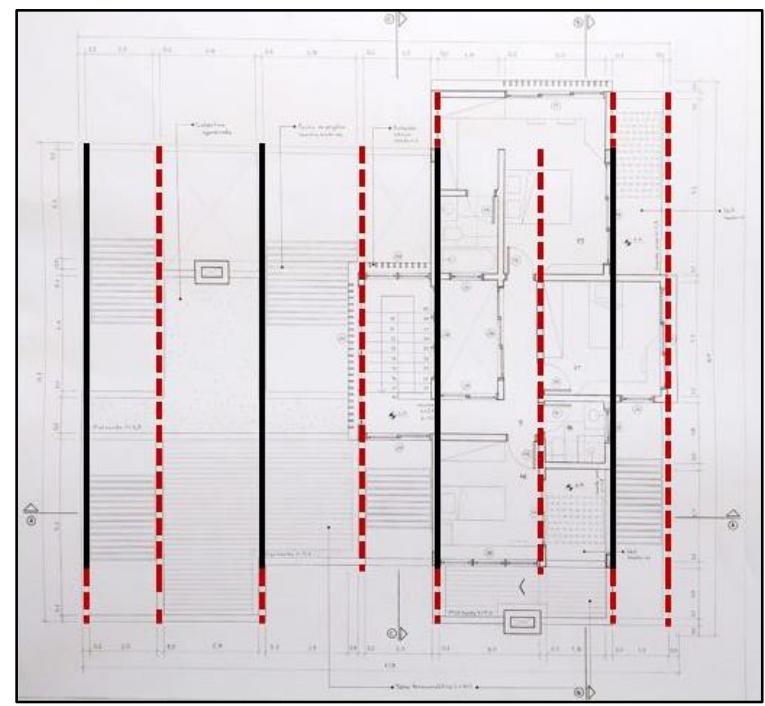

\subsection{Arranjo Espacial}

A proposta contemplou uma discussão acerca da mutualidade entre os espaços interno e externo. Os elementos do programa, nesse sentido, associando-se à nova conformação atribuída ao subsistema estrutural, foram distribuídos em uma alternância de cheios e vazios. Isso permitiu uma organização fragmentada do programa, ressingnificando a relação entre os ambientes - que estão entre o estar dentro e fora da Casa - e, ao mesmo tempo, possibilitando a compreensão do conjunto como unidade conexa.

Aos módulos vazios, nesse contexto, atribuiu-se a função de exaltar a continuidade estrutural - em uma associação ao conceito de tectonicidade -, valorizando os vãos por onde os jardins se fazem presentes e evidenciando a amplitude da edificação, uma vez que os limites da construção passaram a ser os extremos da estrutura. Observa-se, além disso, que tal distribuição permitiu qualificar os espaços internos, visto a maior permeabilidade à insolação e à ventilação, sobretudo.

A organização do espaço arquitetônico foi mediada pela aplicação de uma configuração linear de circulação, associada a um núcleo de circulação vertical central - que se prolonga ao térreo, possibilitando acesso secundário. Obteve-se, por conseguinte, uma circulação independente e a consequente relação direta entre todos os elementos do programa.

Ao segundo pavimento do "terreno vertical", de maior área, destinou-se a ocupação pelos ambientes sociais e de serviços: sala de estar e jantar, espaço gourmet (churrasqueira), cozinha, lavabo, área de serviço, despensa, escritório (com a possibilidade de acesso independente), bem como um conjunto de varadas - relacionadas aos módulos vazios. Coube, portanto, ao terceiro pavimento, de menor área, abrigar os ambientes íntimos: dois quartos, banheiro social e suíte. $\mathrm{O}$ térreo, por sua vez, ocupou-se pelo abrigo para veículos e pelo prolongamento da circulação vertical - que comporta, aos fundos, uma cisterna e filtros, associados a um sistema de captação de águas pluviais. 
Figura 7 - Relação estabelecida entre os espaços interno e externo (em azul e verde, respectivamente) visualizada na plantas baixas do segundo (a) e terceiro pavimento (b)

(a)

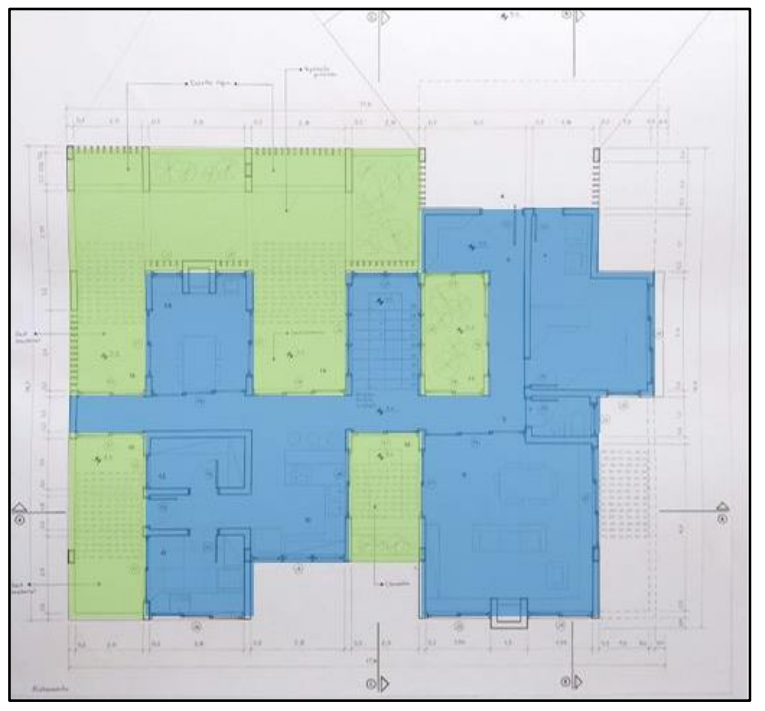

(b)

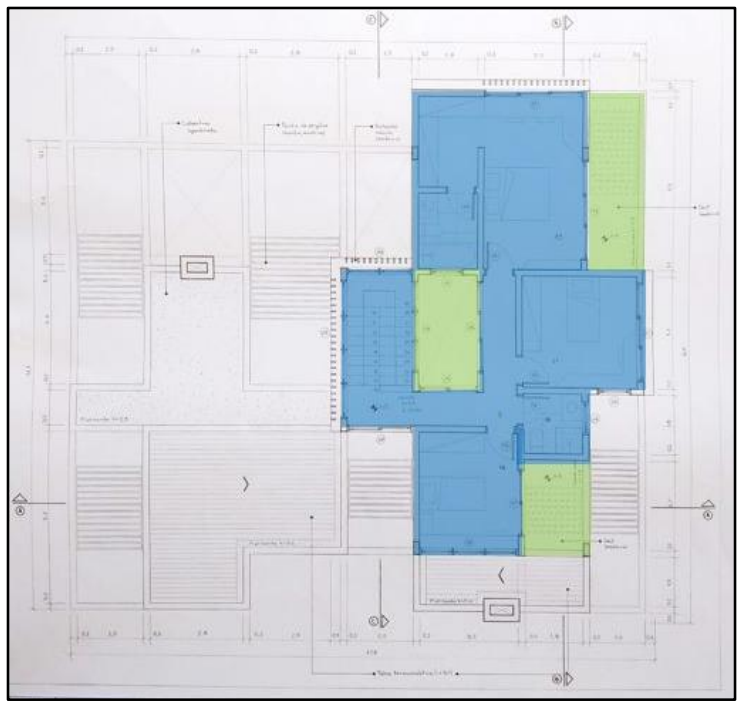

Figura 8 - Configuração atribuída à circulação (em vermelho) visualizada na plantas baixas do segundo (a) e terceiro pavimento (b)

(a)

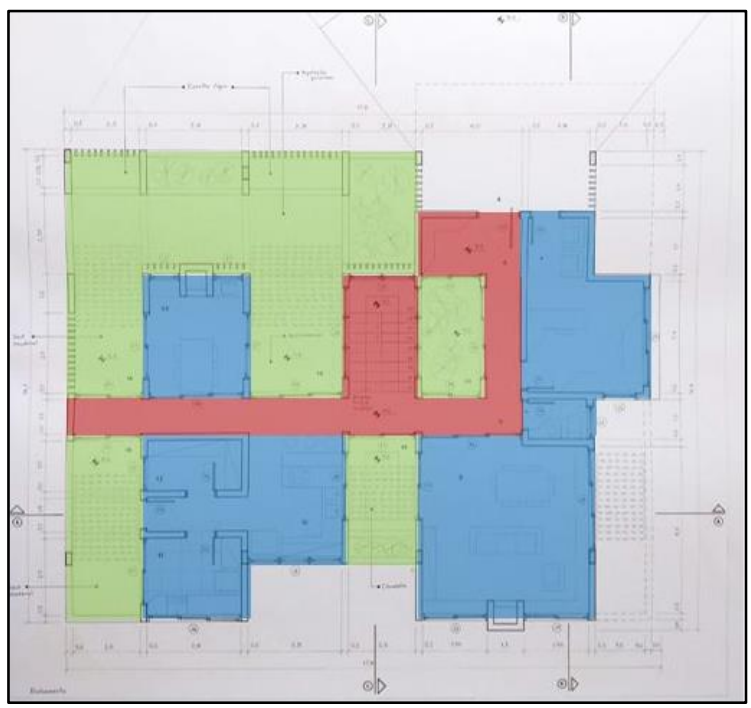

(b)

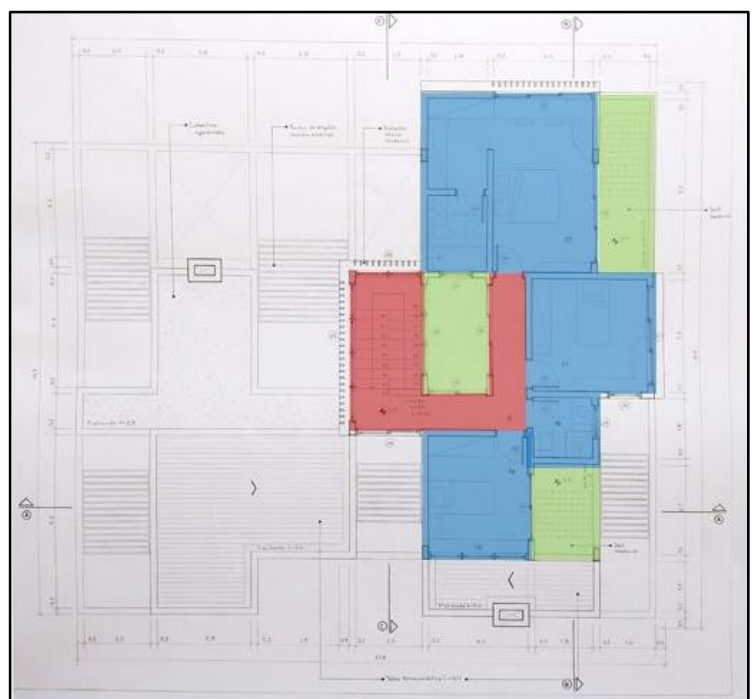


Figura 9 - Arranjo espacial da Casa Permeável: plantas baixas do térreo (a), segundo (b) e terceiro pavimento (c)

(a)

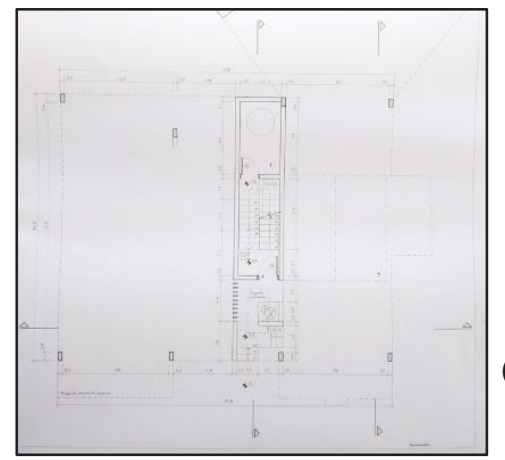

(b)

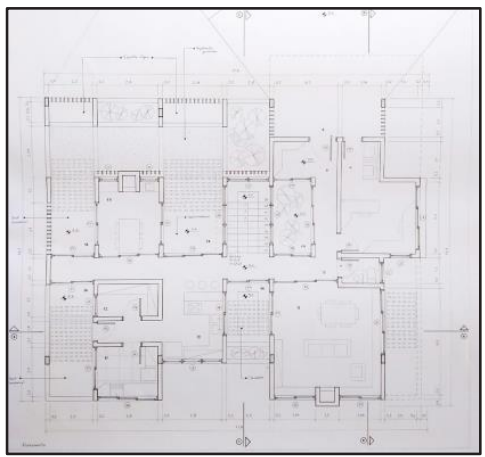

(c)

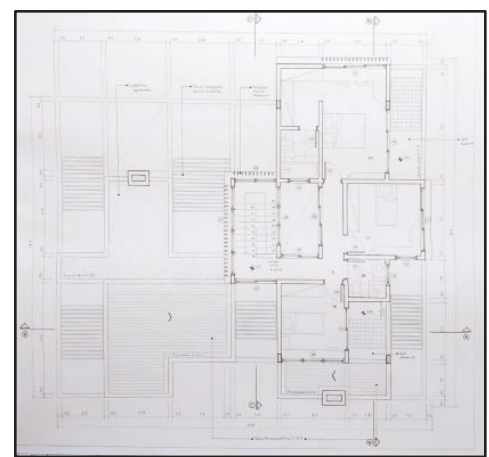

\subsection{Aperfeiçoamento Compositivo}

É necessário ressaltar que o partido arquitetônico da Casa Permeável, em síntese, deriva-se quase que exclusivamente destas experimentações elementares que perseguem o espaço através da estrutura. É incontestável, entretanto, o fato de que, posteriormente à compreensão da espacialidade do contexto estrutural preexistente, realizaram-se aprimoramentos volumétricos para garantir o equilíbrio da composição. Esses associaram-se, também, ao atendimento de algumas necessidades funcionais da edificação, a exemplo da disposição superior do reservatório de água e da ocultação do telhado por platibandas.

Figura 10 - Perspectivas da Casa Permeável: vista superior a partir da fachada sudoeste (a), composição das fachadas nordeste (b), vista a partir da fachada sudeste, aos fundos (c)

(a)
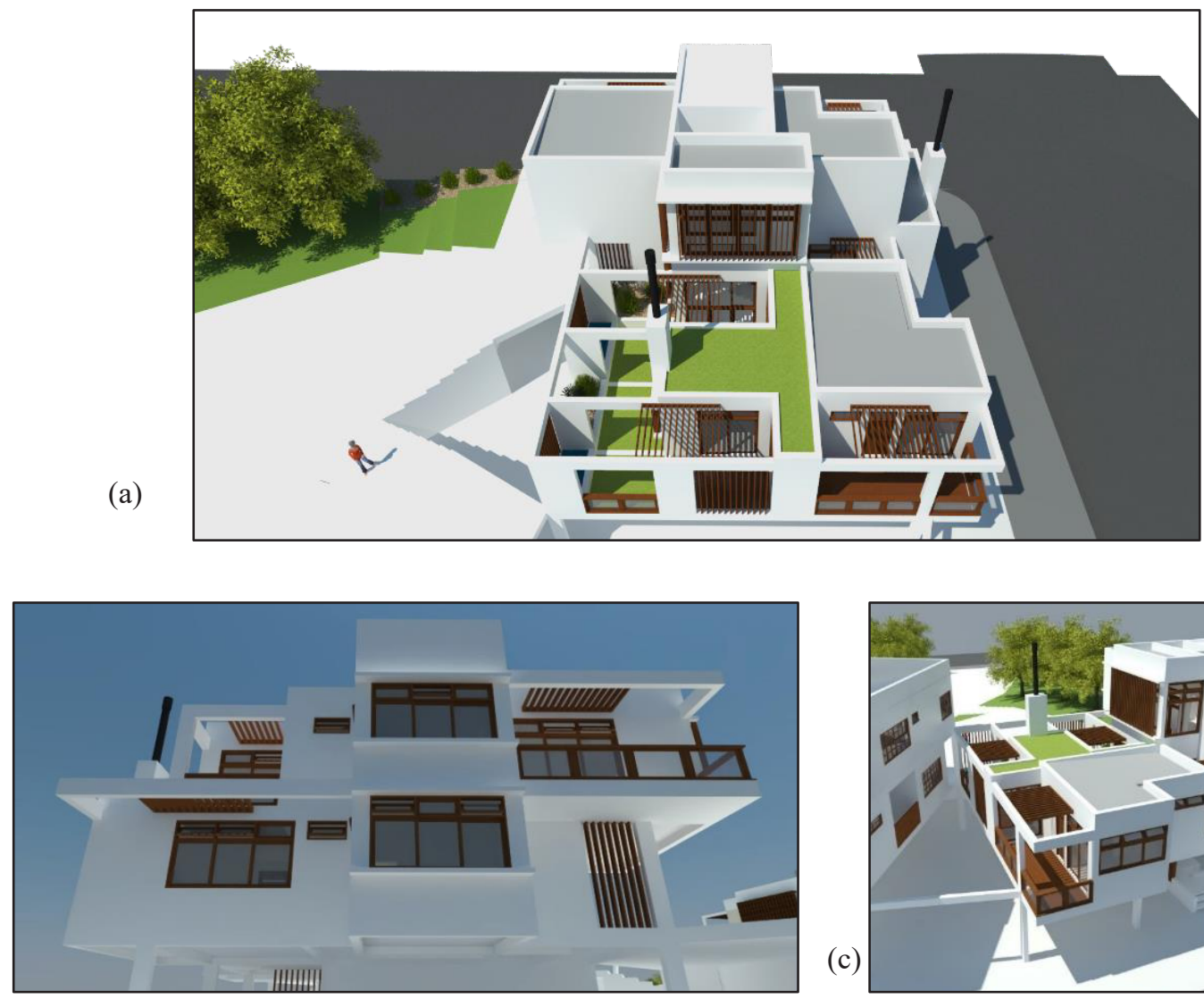

(c)

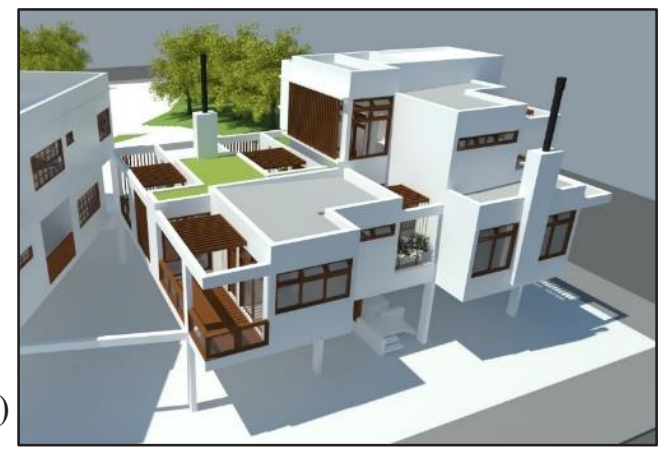


Notabiliza-se, nesse sentido, que os aperfeiçoamentos compositivos - bem como os elementos adicionados - que sucederam a ordenação espacial e estrutural estavam estreitamente relacionados a estratégias bioclimáticas e tecnológicas que objetivavam qualificar a proposta. Cita-se, quanto a isso, a aplicação de uma cobertura verde sobre o espaço gourmet e a circulação horizontal do segundo pavimento; o desenho das esquadrias, que apresentam basculantes superiores, sobretudo para exaustão do ar quente (efeito chaminé), bem como seus posicionamentos estratégicos, potencializando a ventilação, principalmente de modo cruzado, e possibilitando a exploração da iluminação natural; a utilização de proteções solares verticais fixas em madeira nas fachadas noroeste e sudoeste; a elevação do volume referente à caixa de escada a fim de propiciar a exaustão do ar quente dos ambientes adjacentes.

Por fim, observa-se a atribuição, a este processo compositivo, de discussões acerca da relação de complementaridade entre módulos e mobilidade. Contrapondo-se à rigidez subentendida pela estrutura, o projeto contemplou a maleabilidade através da aplicação de painéis compostos de pérgulas materializadas em madeira - inspiradas na proposta do FGMF Arquitetos para a Casa das Pérgolas Deslizantes. Suspensas junto às vigas em evidência podem ser movimentadas longitudinalmente à modulação estrutural, em concordância às condições climáticas e uso dos espaços. A flexibilidade desses elementos estabeleceu uma associação à reconfiguração do ambiente pelos usuários e, nesse sentido, à apreensão do espaço externo como parte integrante da edificação.

\section{Considerações finais}

A partir das experiências descritas neste artigo, conclui-se que o processo de projeto na arquitetura, de modo geral, não admite a adoção de uma única metodologia. Raciocínios uniformes tendem a atingir soluções convencionais. É notório, nesse sentido, que são diversos os caminhos para atingir resultados semelhantes. Os resultados, entretanto, manifestam - ou podem manifestar - a metodologia aplicada. Isso foi o que ocorreu com a Casa Permeável, ao evidenciar a estrutura em sua composição final.

Observa-se, por fim, que a metodologia adotada nas circunstâncias citadas mostrou-se favorável para solucionar as problemáticas propostas, sobretudo por embasar-se na progressão de raciocínios elementares, que possibilitaram a inversão de processos tradicionais.

\section{Agradecimentos}

O primeiro autor agradece às colegas Andreza Oliveira Nunes, Júlia Heloísa de Souza Lima, Manoela da Rosa Salvador e Rayana Pinheiro, que compuseram seu grupo de trabalho, visto que todos os raciocínios que antecederam a concepção da Casa Permeável foram fruto de construções coletivas. Por conseguinte, também agradece às colegas mencionadas por cederem o uso das imagens, ressaltando que a fonte da maior parte das figuras que ilustram este artigo é atribuída ao primeiro autor.

O primeiro autor agradece também aos professores Ricardo Souza Rocha e Samuel Silva de Brito pelas experiências propiciadas através da disciplina. Em especial ao professor Samuel, pelo acolhimento como orientador, pela paciência, dedicação e ensinamentos que possibilitaram a elaboração deste artigo. 


\section{Referências}

ARCHDAILY [Internet]. Casa das Pérgolas Deslizantes / FGMF Arquitetos. [cited 2017 apr 21]. Available from: https://www.archdaily.com.br/br/759465/casa-das-pergulas-deslizantes-fgmf-arquitetos.

PORTAL VITRUVIUS. Casa Grelha. No sopé da Serra da Mantiqueira. [Internet]. 2008 [cited 2017 apr 21]; 8(92.01). Available from: http://www.vitruvius.com.br/revistas/read/projetos/08.092/2918.

ROCHA, Ricardo S. Atelier em Processo: uma Proposta de Projeto e Ecologia da Paisagem. In: XXXVI ENSEA - Encontro Nacional sobre Ensino de Arquitetura e Urbanismo: Ensino e Aprendizagem presencial e o Papel Social do Arquiteto e Urbanista; 2017; Brasília, Brasil.

SUMMA+. Densidade Residencial. [Internet]. $2016 \quad$ [cited 2018 apr 21]; (148). Available from: http://www.revistasummamas.com.ar/pt/revista/148. 